\title{
UNIFIED POWER FLOW CONTROLLER USED POWER SYSTEM STABILITY ENHANCEMENT UNDER THREE PHASE FAULT
}

\author{
Vikramarajan Jambulingam ${ }^{1}$ \\ ${ }^{1}$ Electrical and Electronics Engineering, VIT University
}

\begin{abstract}
In this research paper stability of power systems are analyzed by using an UPFC. Actually UPFC controls voltages at bus, real and reactive power flow in transmission lines by means of controlling approximately its series and shunt parameters. Generally Unified power flow controller enhances the power system stability under three phase fault. The control strategy is implemented by Unified power flow controller devices and it is found that system performance is enhanced under three phase fault. Due to three phase fault the problems arises in generator voltage, generator current, Infinite bus voltage, Infinite bus current and generator load angle of a power system are investigated in detail and resolved by designing and testing a test system using MATLAB/SIMULINK.
\end{abstract}

Keywords: UPFC, FACTS, Transient stability

\section{INTRODUCTION}

The power generation and transmission is a complex process, requiring the working of many components of the power system in tandem to maximize the output. The shunt faults are the most regular type of faults taking place in the field [1]. Three phase faults caused due to falling tower, failure of equipment (or) even a line braking and touching the remaining phases can cause three phase faults [2]. The Flexible AC transmission system [FACTS] proposed in 1995.

The basic purpose of FACTS is installing the power electronics devices at the high voltage side of the power grid to make the complete system electronically controllable. Because of high power semiconductor devices and control technology FACTS devices plays a vital role in power systems. Unified Power Flow Controller is the most versatile and complex of the facts devices. It is the combined features of STATCOM and SSSC.

Three most important reasons for using UPFC are as follows:

1. Passes reactive power flow birectionally.

2. Maintaining well regulated DC voltage.

3. Workability in wide range of operating condition.

Limying charren et al., investigated the effects of unified power flow controller [3]. No roozianetal., reported about the use of UPFC for optimal power flow control [4]. Fujita et al., explained the control and analysis of unified power flow controller [5].In the transmission line by connecting UPFC the real and reactive power is controlled [6]. Mete et $a l$., developed a mathematical model for analysis of unified power flow controller [7].

In this paper the control strategy is implemented using UPFC devices. It is found that, system stability is enhanced under three phase fault. Similarly five parameters are investigated in detail by designing and testing a test system using MATLAB/SIMULINK.

Five different Parameters are represented as follows:

1. Generator Voltage as $\left[\mathrm{V}_{\mathrm{g}}\right]$

2. Generator Current as $\left[I_{g}\right]$

3. Infinite Bus Voltage as $\left[\mathrm{V}_{\mathrm{b}}\right]$

4. Infinite Bus Current as $\left[\mathrm{I}_{\mathrm{b}}\right]$

5. Generator load angle as $[\partial]$

\section{BLOCK DIAGRAM OF TEST SYSTEM}

The below test network is tested and parameters such as generator voltage, generator current, bus voltage, bus current and generator load angle performances are examined by connecting UPFC devices.

Table.1.Test system specification

\begin{tabular}{|l|l|l|l|}
\hline \multicolumn{4}{|l|}{ Test system specification } \\
\hline S.No. & Generator 1 & Generator 2 & STATCOM \\
\hline 1. & $10 \mathrm{KV}$ & $10 \mathrm{KV}$ & $10 \mathrm{KV}$ \\
\hline 2. & $110 \mathrm{MW}$ & $10 \mathrm{MVAR}$ & $10 \mathrm{MVAR}$ \\
\hline 3. & $300 \mathrm{RPM}$ & NA & NA \\
\hline
\end{tabular}

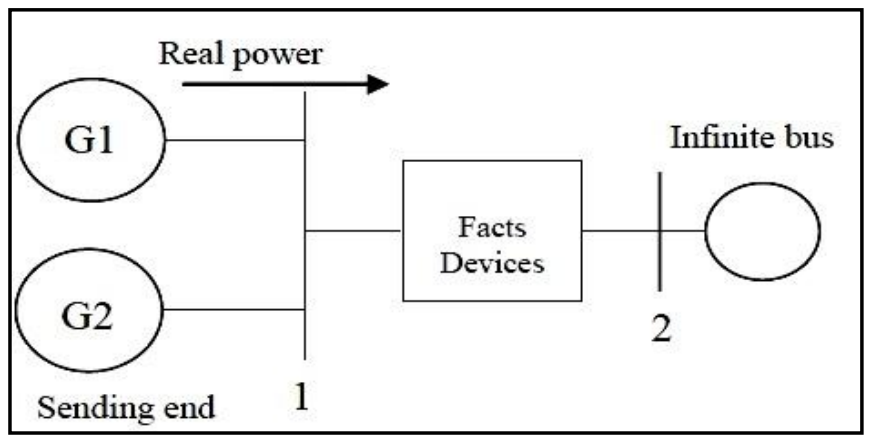

Fig.1.Test system with FACTS device 


\section{DESIGN AND WORKING OPERATION OF UNIFIED POWER FLOW CONTROL}

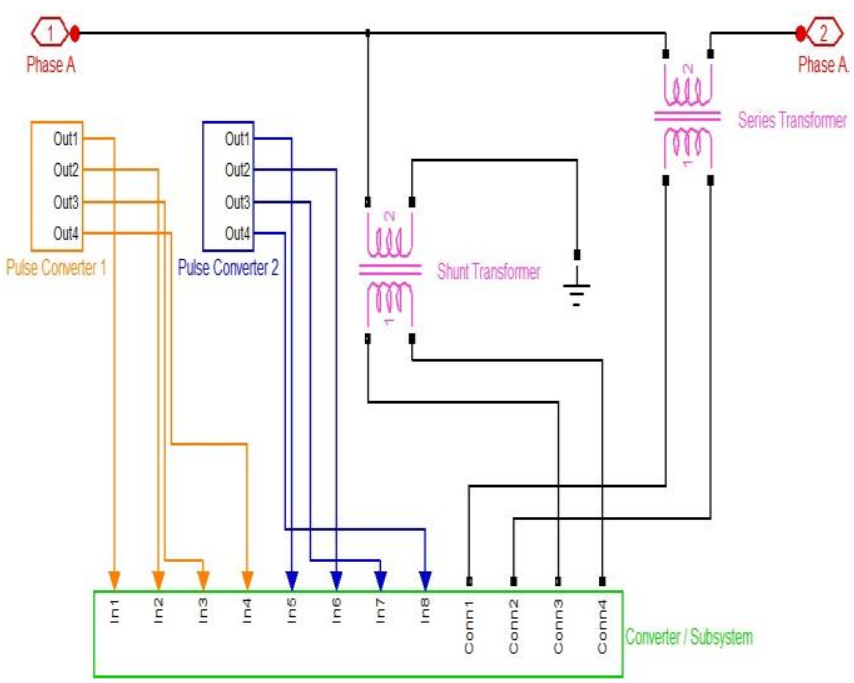

Fig.2.Design of Unified power flow controller

The components of UPFC are two voltage source converters sharing a common DC storage capacitor and connected to the power system through coupling transformers.DC link creates path for active power exchange between the converters.

In unified power flow controller the transmitted power can be controlled by changing three parameters, they are as follows:

1. Transmission magnitude voltage

2. Impedance

3. Phase angle
The unified power flow controller is the most gifted version of FACTS devices and it serves to control simultaneously all the above three parameters [voltage, impedance and phase angle] at the same time.

The Phase [A] design of UPFC [Unified power flow controller] is shown in figure.2.Voltage source converter 1 connected in shunt through shunt transformer. The shunt inverter operates as a STATCOM and generates or absorbs reactive power to regulate voltage magnitude at connection point. Voltage source converter 2 connected in series through series transformer and generates or absorbs reactive power to regulate current flow.

UPFC can also provide simultaneous control of all basic power system parameters through transmission voltage, impedance and phase angle.

\subsection{Procedure to Build Up a Test System}

Step 1: Design a Test system and create three phase faults near infinite bus as shown in figure 3 .

Step 2: Measure the generator voltage, generator current, Bus voltage, Bus current and generator load angle.

Step 3: Design a Thyristor controlled series compensation (Figure.2) and connect to the test system as shown in figure.4.

Step 4: Measure the generator voltage, generator current, Bus voltage, Bus current and generator load angle.

Step 5: Compare both the result of test system as shown in table.2.

\section{SIMULATION MODEL OF TEST SYSTEM}

\subsection{Test System with Three Phase Fault}

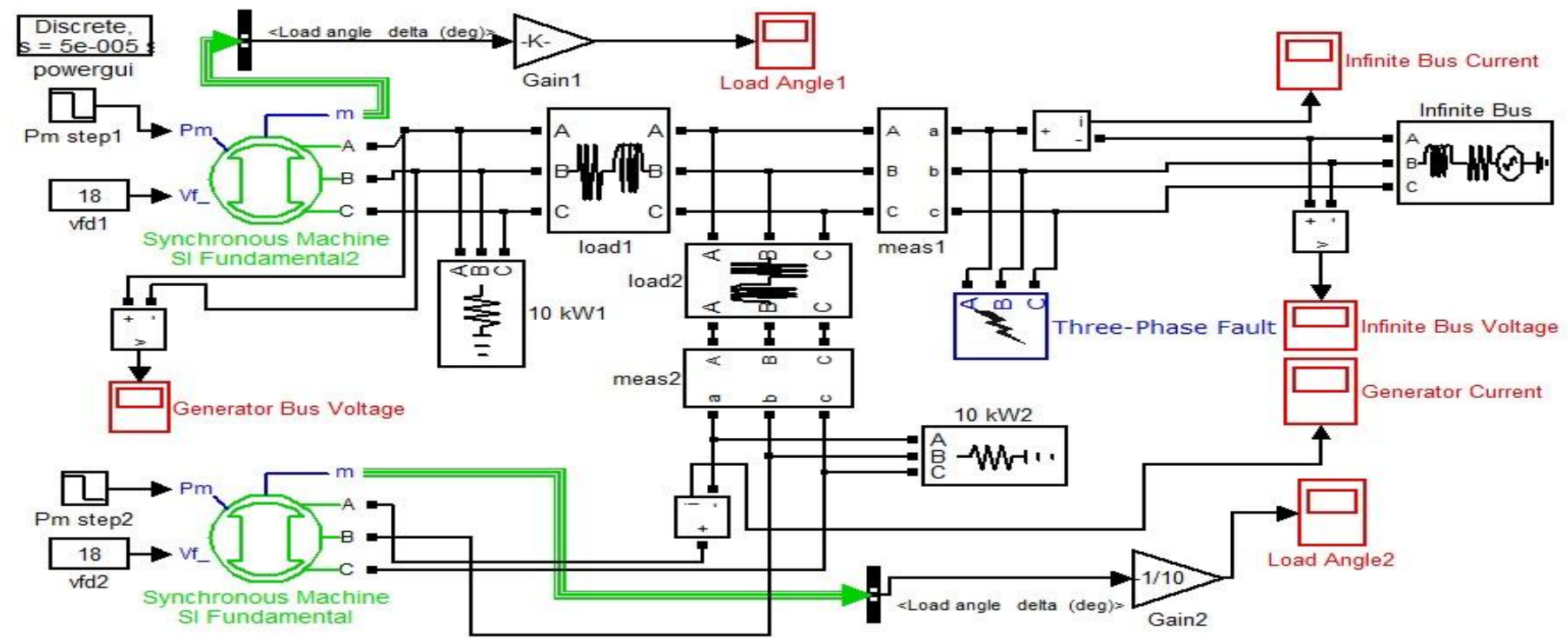

Fig 3. Test system with three phase fault 


\subsection{Test System with Thyristor Controlled Series Compensation}

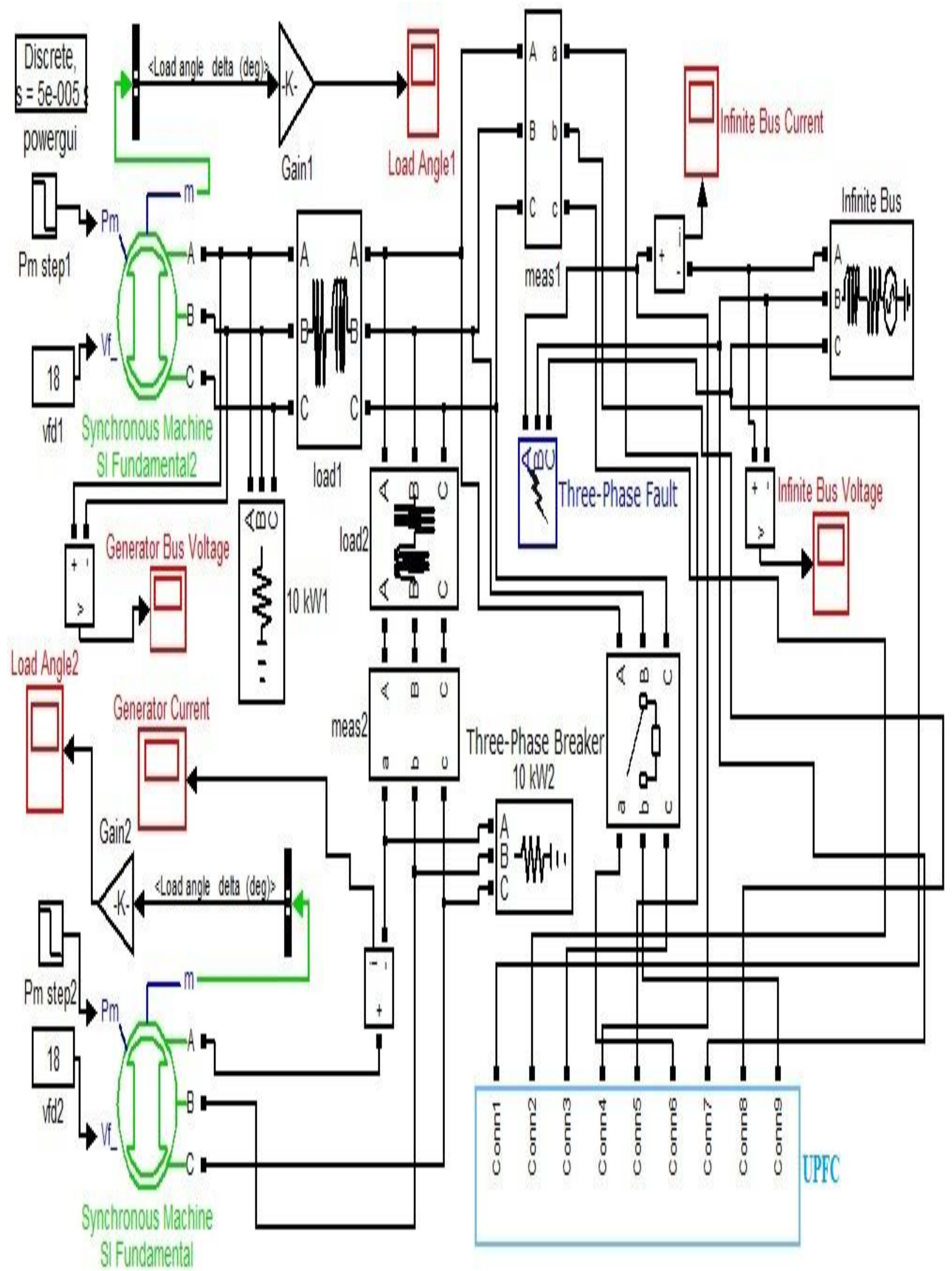

Fig.4. Test system with Unified power flow controller 


\section{SIMULATION RESULTS}
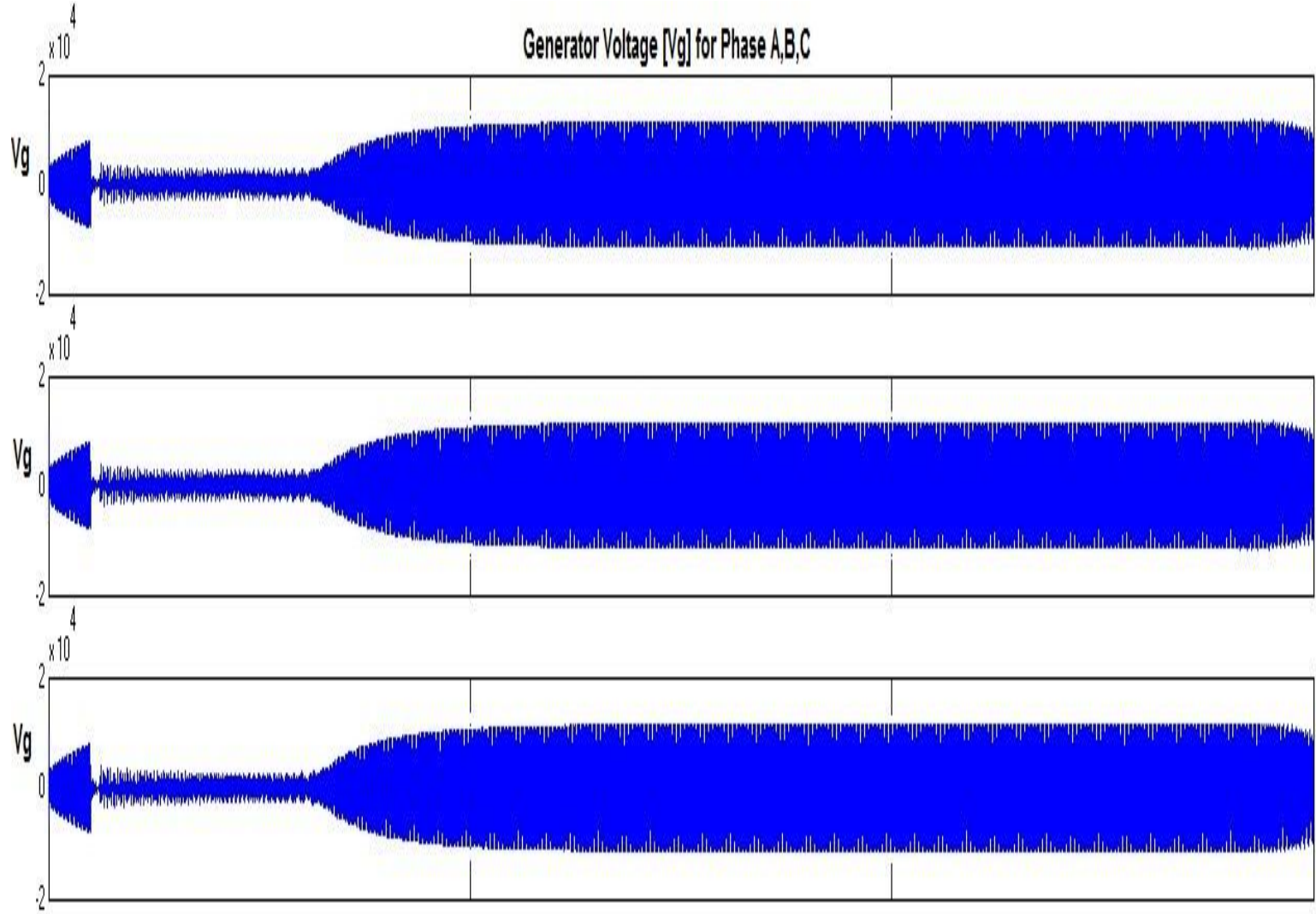

Generator Curent" (laj for Phase A,B,C
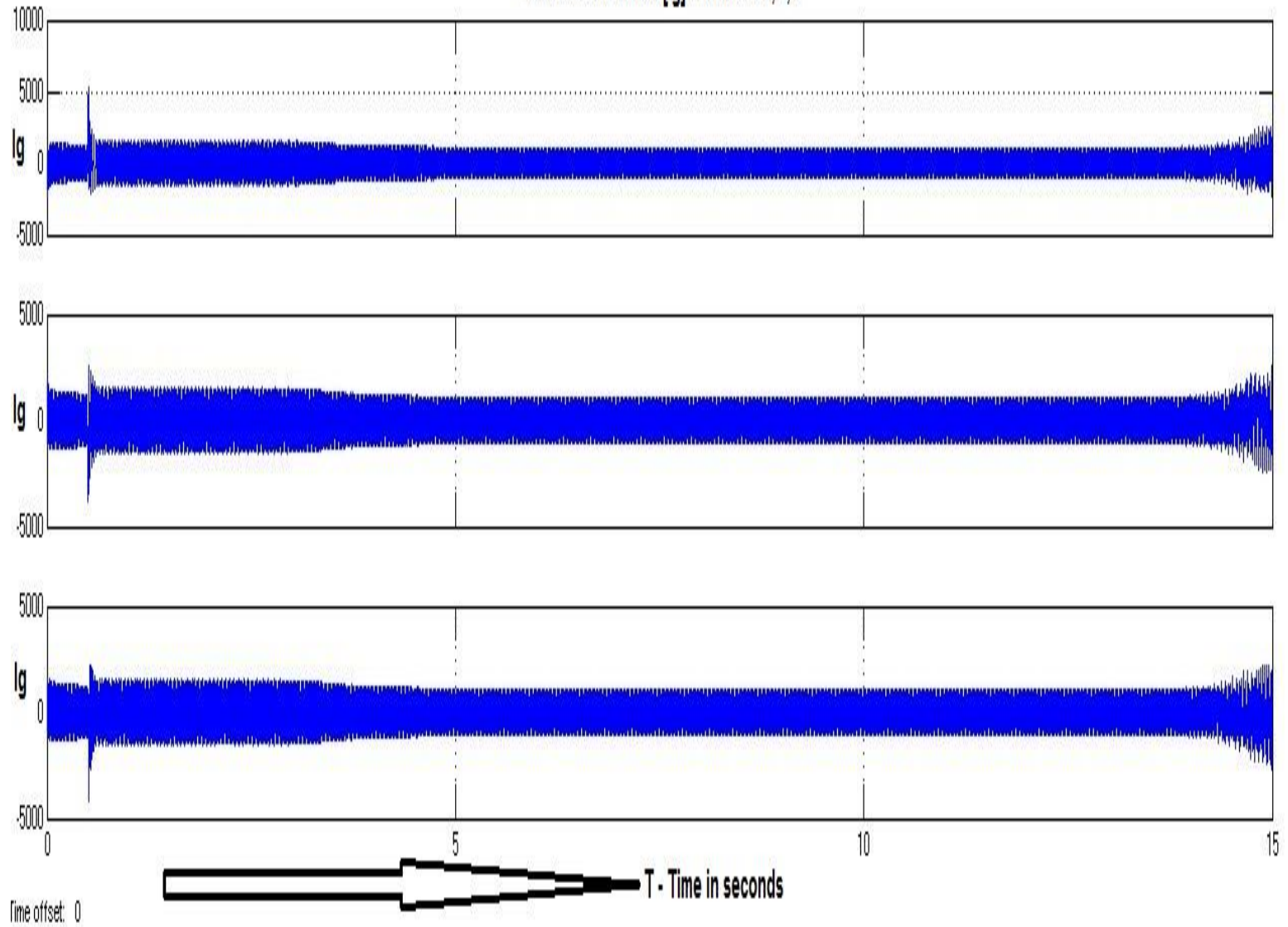

Fig.5.Represents generator voltage and current of test system with three phase fault 

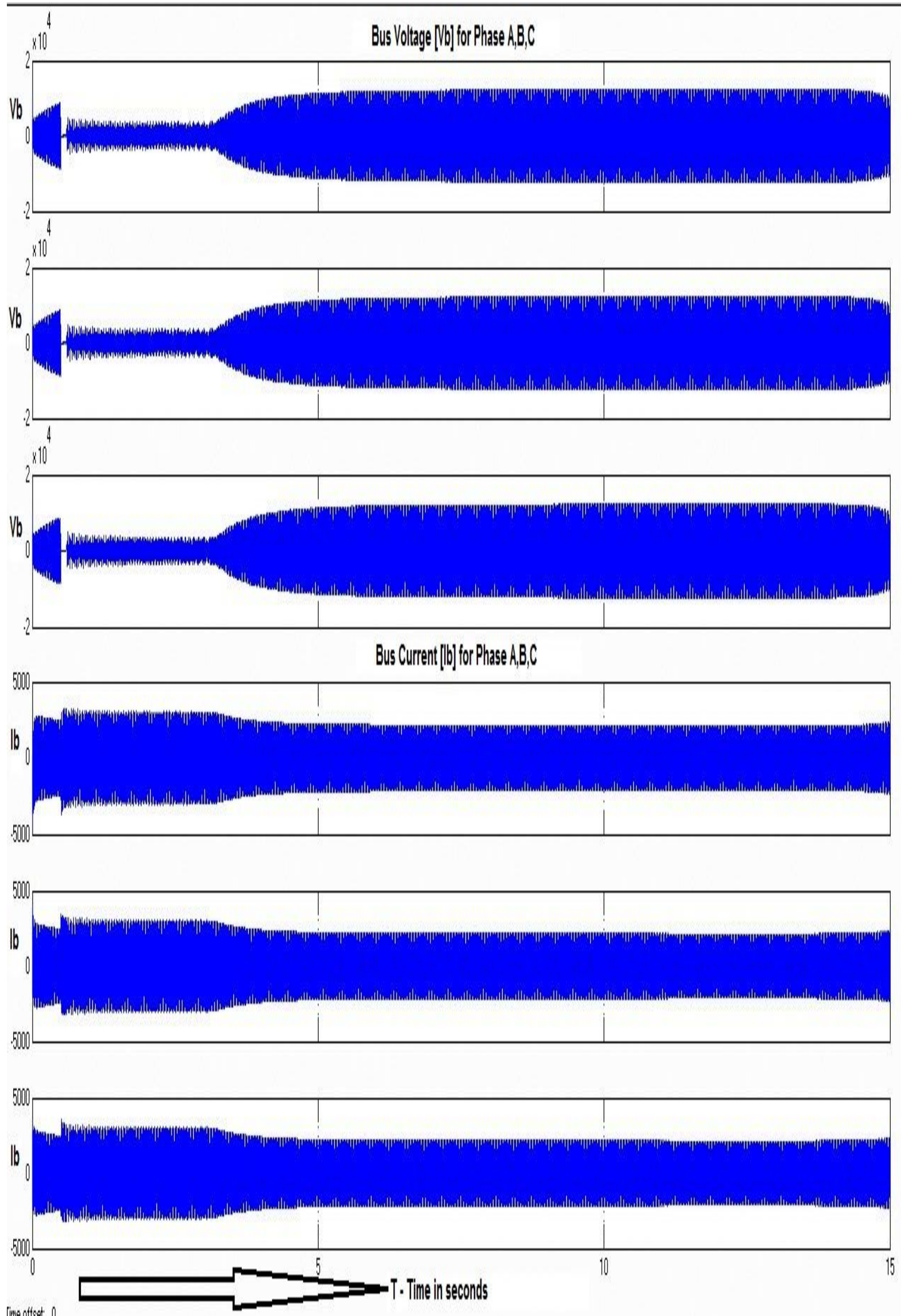

Fig.6.Represents bus voltage and current of test system with three phase fault 

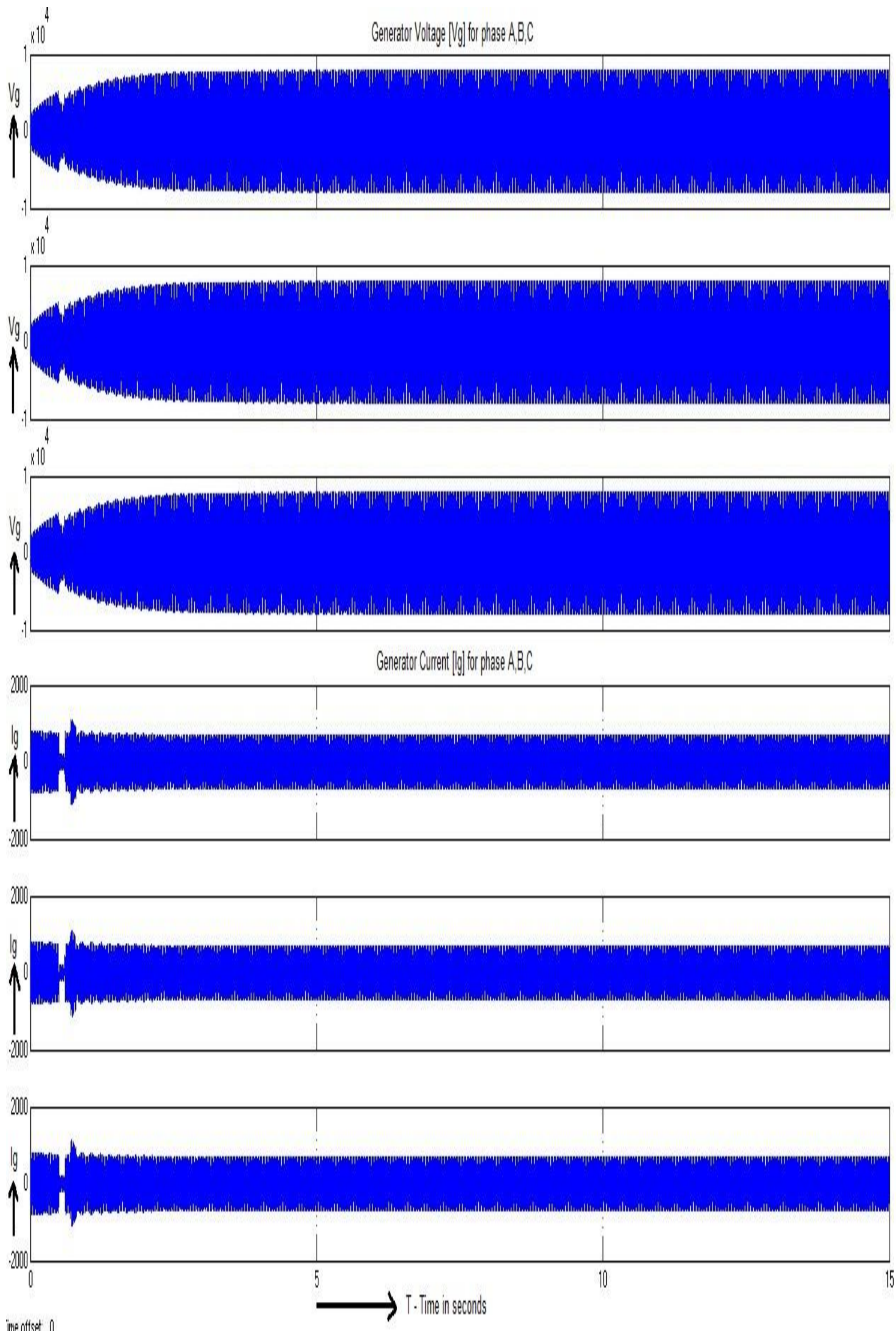

Fig.7. Represents generator voltage and current of test system with UPFC 

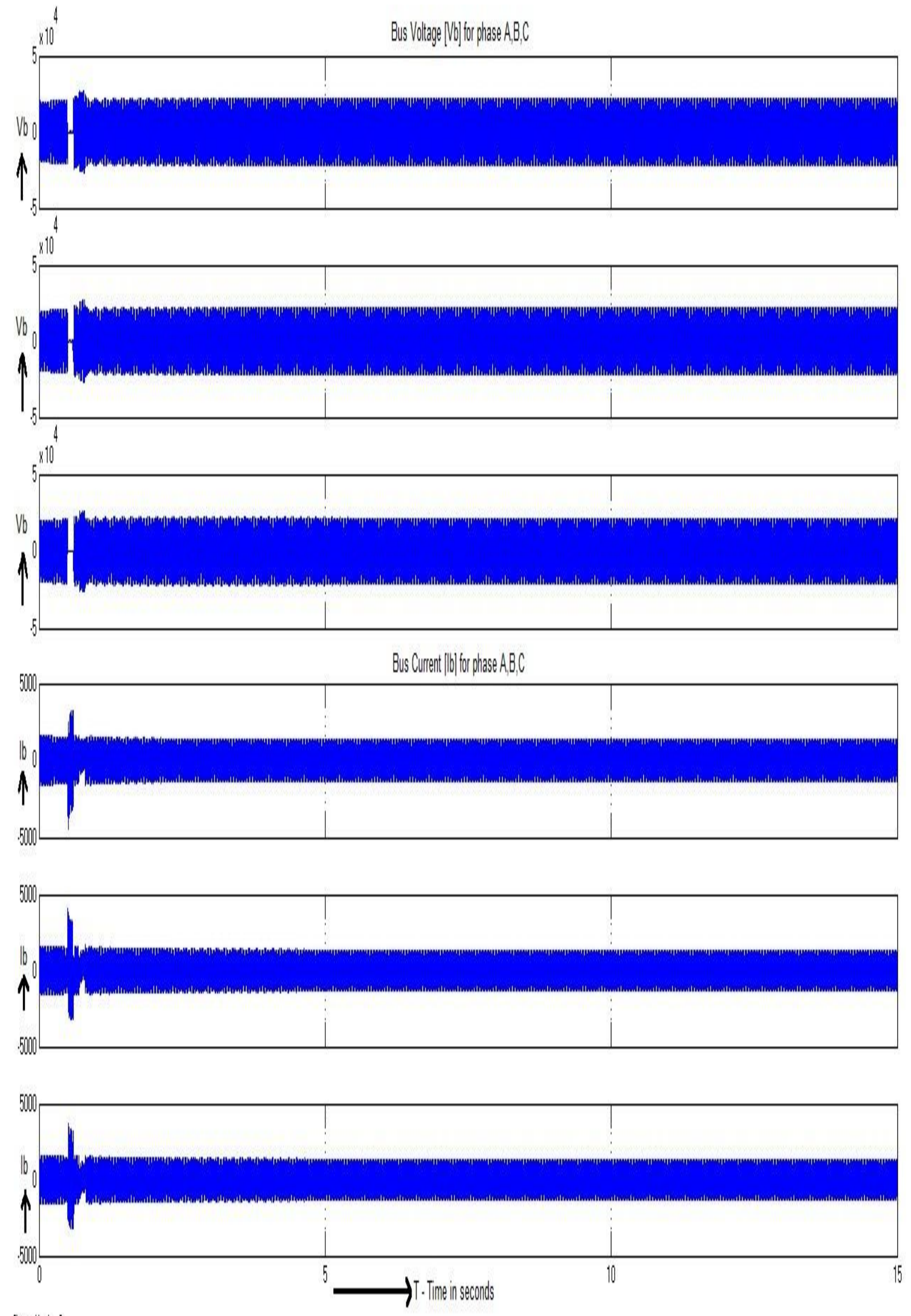

Iime offsst: 0

Fig.8. Represents bus voltage and current of test system with UPFC 

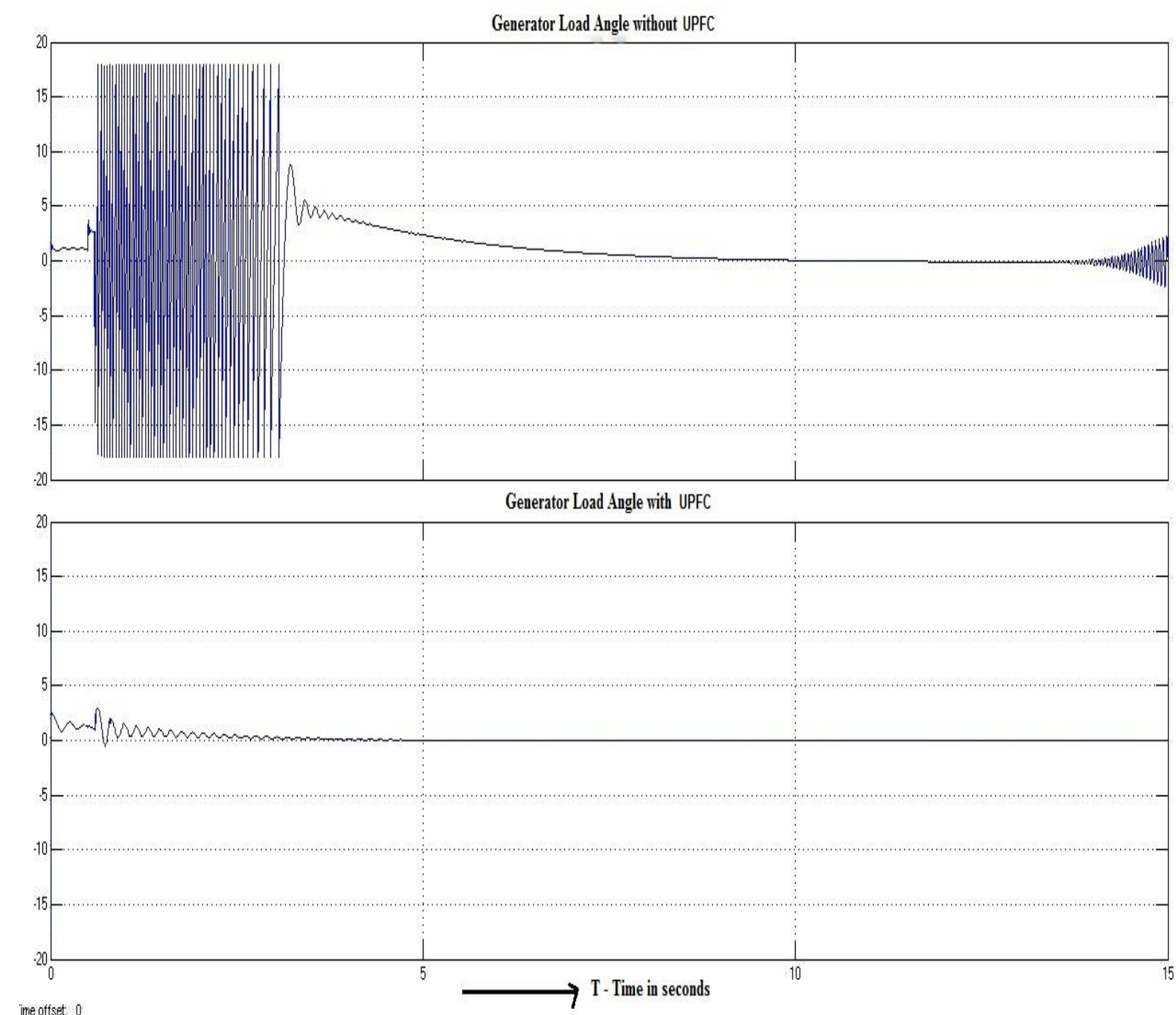

Fig.9.Represents Generator load angle of test system with and without UPFC

Table 2 Test system settling time comparisons

\begin{tabular}{|l|l|l|}
\hline \multirow{2}{*}{ Parameters } & \multicolumn{2}{|l|}{ Settling Time $\mathbf{T}_{\mathbf{s}}$} \\
\cline { 2 - 3 } & $\begin{array}{l}\text { Without } \\
\text { FACTS } \\
\text { devices }\end{array}$ & $\begin{array}{l}\text { Thyristor } \\
\text { controlled series } \\
\text { compensation }\end{array}$ \\
\hline $\begin{array}{l}\text { Generator } \\
\text { voltage }\end{array}$ & 4.3 Seconds & 1.3 Seconds \\
\hline Bus voltage & 5.3 Seconds & 0.2 Seconds \\
\hline $\begin{array}{l}\text { Generator } \\
\text { current }\end{array}$ & 4.3 Seconds & 2.2 Seconds \\
\hline $\begin{array}{l}\text { Bus current } \\
\text { Generator } \\
\text { load angle }\end{array}$ & 3.3 Seconds & 0.1 Seconds \\
\hline
\end{tabular}

From Figure 5, 6, 7 and 8 we can observe that the generator voltage and current settling time is highly reduced from 4.3 seconds to 1.3 seconds and from 4.3 seconds to 2.2 seconds respectively. Likewise the Bus voltage and current settling time is highly reduced from 5.3 seconds to 0.2 seconds and from 3.3 seconds to 0.1 seconds respectively. So the power system stability is achieved moderately better with thyristor controlled series compensation under three phase fault in the test system.

\section{CONCLUSIONS}

In this research paper the test system is designed with three phase fault using Unified power flow controller. By using the Unified power flow controller in the test system the bus voltage are controlled and voltage fluctuation is reduced. Generator voltage is stabilized at 1.3 seconds. Likewise the generator current is stabilized at 2.2 seconds. But without FACTS device generator voltage and generator current reaches stabilization at 4.3 and 4.3 seconds respectively. From the table. 2 we infer that the test system with UPFC is much better in stabilization of generator load angle, Infinite Bus voltage and current than without FACTS device. 


\section{REFERENCES}

[1]. C.L.Wadhwa, "Electrical Power System", pp.306, New Age International, 2006.

[2]. Hadi Saadat, "Power system analysis" TATA McGrawHill edition, 2002.

[3]. S.Limyingcharren, U.D.Annakkage and N.C.Pahalawaththa, "Effects of Unified Power Flow Controllers on Transient Stability", IEEE Proceedings Generation Transmissions and Distribution, 145(2), 1998, pp.182-188.

[4]. M.Noroozian, L.Anguist, M.Ghandhari and G.Andersson, "Use of UPFC for Optimal Power Flow Control, IEEE Trans. On Power Delivery, Vol.17, No.4 [1997], pp.1629-1634.

[5]. H.Fujita, Y.Watanabe and H.Akagi, "Control and Analysis of Unified Power Flow Controller", IEEE Transaction on Power Electronics, 14(6)1999, pp.10211027.

[6]. S.Tara Kalyani and G.Tulasiram Das, "Simulation of Real and Reactive Power Flow Control with UPFC Connected to a Transmission Line", Journal of Theoretical and Applied Information Technology, 2008.

[7]. A.Mete Vural and Mehmet Tumay, "Mathematical Modeling and Analysis of a Unified Power Flow Controller: A Comparisons of Two Approach in Power Flow Studies and Effects of UPFC Location", Electrical Power and Energy Systems, Vol.29, pp.617-629, 2007.

\section{BIOGRAPHIE}

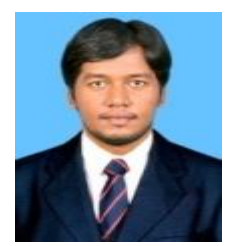

Mr.J.Vikramarajan received his Master degree in Power Electronics and Drives and Bachelor degree in Electrical and Electronics Engineering from VIT University, India. His research interests are power electronic applications, power quality, power electronic converters and power electronic controllers for renewable energy systems. 